\title{
Insulin -like Growth Factor 1 in Adolescent Girls with Anorexia Nervosa: Relation to Bone Formation Parameters
}

\section{Rasha T Hamza ${ }^{1}$ and Doaa H Hewedi ${ }^{2 *}$}

${ }^{1}$ Department of Pediatrics, Ain Shams University, 21 Mahmoud El Badry Street, Nasr City, Cairo, Egypt

${ }^{2}$ Department of Psychiatry, Faculty of Medicine, Ain Shams University, 21 Mahmoud El Badry Street, Nasr City, Cairo, Egypt

"Corresponding author: Dr. Doaa H Hewedi, MD, Department of Psychiatry, Faculty of Medicine, Ain Shams University, 21 Mahmoud El Badry Street, Nasr City, Cairo, Egypt, Tel: + 202 26710897; Fax: + 20 226710897; E-mail: doaahewedi20042000@yahoo.com

Received: Apr 01, 2014; Accepted: Aug 04, 2014; Published: Aug 20, 2014

Copyright: $\odot 2014$ Hamza RT, This is an open-access article distributed under the terms of the Creative Commons Attribution License, which permits unrestricted use, distribution, and reproduction in any medium, provided the original author and source are credited.

\section{Abstract}

Objective: Puberty is associated with marked changes in body weight and hormonal profile related to pubertal stage such as insulin-like growth factor 1 (IGF-1). These changes are also associated with Anorexia Nervosa (AN) and may impact bone. Thus our study aimed to study bone metabolism and possible etiology of osteopenia in Egyptian adolescent AN girls.

Method: Twenty five adolescent girls were studied compared to 30 healthy age - and pubertal stage- matched controls. All participants were subjected to clinical evaluation, neuropsychiatric assessment, auxological measurements, bone age assessment, bone density and body composition assessment; and measurement of serum growth hormone $(\mathrm{GH})$, IGF-1, ionized calcium, phosphorus, 25 hydroxy vitamin $\mathrm{D}$ [25-(OH)D] and serum osteocalcin (OC).

Results: Lean body mass and Bone Mineral Density (BMD) were significantly reduced in AN patients compared with controls even when controlled for height. Serum GH was elevated significantly in patients $(P=0.02)$. Serum IGF-1 level was reduced significantly in $A N(P=0.0001)$. Serum ionized calcium, vitamin $D$ and $O C$ levels were significantly lower in patients $(P=0.03,0.04$ and 0.02 respectively). IGF- 1 was strongly positively correlated with $O C$ in patients $(r=0.865 ; P=0.001)$. In stepwise regression analysis, IGF-1 caused $73 \%(r 2=0.75 ; P=0.001)$ of variation in OC levels in AN.

Discussion: This study describes low bone formation in AN compared with age - and pubertal stage-matched adolescents. Serum levels of IGF-1 are highly correlated with bone formation and thus, IGF-1 measurement can be used as a marker for bone osteoblastic activity in AN.

Keywords: Anorexia nervosa; Egyptian; Insulin like growth factor-1; Osteopenia

\section{Introduction}

The prevalence of AN is increasing in western societies and its estimated prevalence is $0.2-1.0 \%$ [1]. Osteopenia is a common complication of this disorder, leading to many negative consequences at a young age [2]. Severe degrees of reduced bone mass have been described in young adolescents even during the initial stages of their illness [3].

A significant amount of bone mass is accumulated during adolescence and diseases that affect bone deposition during this time have persistent and severe effects [4]. The onset of anorexia nervosa (AN) during this critical time impedes the achievement of pubertal bone mass [5]. In addition, significant changes in body weight and composition, pubertal development, and pubertal hormones, such as insulin-like growth factor 1 (IGF-1), occur during AN may affect bone [6].

With the background that the abnormalities in bone metabolism in adolescents with $\mathrm{AN}$ and their long-term impact are not completely understood, the aim of this study was to study bone metabolism and the potential causes of osteopenia in adolescent girls with $\mathrm{AN}$ in an Egyptian group in whom nutritional status, bone density, pubertal hormones, and biochemical indices of bone turnover were studied.

\section{Methods}

\section{Participants}

A case-control study was carried out on 25 adolescent girls diagnosed with AN according to the criteria of the Diagnostic and Statistical Manual of Mental Disorders, 4th ed. (DSM-IV) [7]. Patients were recruited from the Outpatient Child Psychiatry Clinic, Institute of Psychiatry and Pediatric Psychiatry Clinic, Children's Hospital, Faculty of Medicine, Ain Shams University (Cairo, Egypt), during March 2010-October 2013.

Of the 25 patients, 22 were recruited from the Outpatient Child Psychiatry Clinic (of whom four patients were referred from the Gastroenterology department with the complaint of persistent vomiting and three patients were referred from the Gynecology department for amenorrhea) and three patients from the Pediatric Psychiatry Clinic. 
Patients with AN were studied in comparison with 30 age - and pubertal stage- matched girls who served as controls. None of the controls had clinical findings indicative of neuropsychiatric manifestations or endocrinal disorders. Exclusion criteria included treatment with estrogen, vitamin $\mathrm{D}$, or calcium before the study or taking medications that might influence the HPA axis. Parents of the patients studied signed an informed written consent for participation in the study. This study was approved by the Bioethical Research Committee, Faculty of Medicine, Ain Shams University Hospitals (Cairo, Egypt).

\section{Procedures}

The studied adolescents were subjected to the following:

(1) Complete assessment of medical history from the patients or their caregivers, with a focus on developmental history, symptoms of malabsorption, for example, abdominal distention, diarrhea with pale foul-smelling, bulky stools, vomiting, poor weight gain, and growth retardation.

(2) Complete clinical examination to exclude other causes of weight loss, for example, malabsorption.

(3) Neuropsychiatric assessment (for patients only)

(a) Patients were diagnosed with AN according to the DSM-IV criteria [7]. Twenty one patients had restricting AN and the remaining four had binge eating/purging AN.

(4) Auxological measurements:

(a) Body weight $(\mathrm{kg})$ was measured on a digital electronic scale. The scale was set to zero before the girl was placed on the scale and was checked weekly using known calibration weights. Weight measurements were taken with the girl wearing little outer clothing and no shoes and then expressed as weight for height standard deviation score (SDS).

(b) Height $(\mathrm{cm})$ was measured without shoes using a wall-mounted Harpenden stadiometer and then expressed as height for age SDS.

(c) BMI is defined as weight $(\mathrm{kg}) /$ height $(\mathrm{m} 2)$. SDSs of height for age and weight for height were calculated according to the norms of Tanner et al. [8] and that of BMI were calculated according to the norms of Cole et al. [9].

(5) BA assessment: BA was determined in all patients with AN and controls by plain radiograph of the left hand and wrist using the method of Greulich and Pyle [10].

(6) Bone density and body composition: areal bone mineral density $(\mathrm{BMD}, \mathrm{g} / \mathrm{cm} 2)$ was measured at the whole body, the posteroanterior lumbar spine (L1-L4), and the left femoral neck, and the whole body composition parameters [whole-body bone mineral content (BMC) $(\mathrm{g})$, lean body mass $(\mathrm{g})$, whole-body fat $(\mathrm{g})$, and percentage body fat] were also determined for each individual at the Institute of Postgraduate Childhood Researches, Ain Shams University. All the parameters mentioned above were determined usingthe Hologic QDR Discovery DEXA fan-beam scanner (software v. 12.3, Hologic, Inc. Company, Bedford, USA; fast-array mode). Calibration stability was monitored using two site-specific phantoms (hologic anthropomorphic spine and whole body phantoms). The precision errors for BMD and BMC are less than $1 \%$ for the spine phantom and less than $2.5 \%$ for the whole-body phantom. This software release has special features for pediatric and adolescent scans. The spine, hip, and whole-body analyses used an automatic low bone density detection algorithm that increases the sensitivity of finding low-density bone. For hip and spine scans, two bone detection thresholds were applied to all scans [11].

Precautions taken before DEXA scanning were as follows:

(1) Artifacts including enteric tubes, metallic objects, and jewelry were excluded from the image [12].

(2) Sedatives were administered to some girls in order to ensure their stability throughout the scanning time, especially during the whole-body scan (which takes longer) [13].

\section{Laboratory investigations}

(a) Serum IGF-1 and GH levels were analyzed using commercial reagents (Incstar Corporation, Stillwater, Minnesota, USA) after extraction of the plasma samples with acid ethanol. Serum basal growth hormone $(\mathrm{GH})$ was determined using commercial reagents (Pharmacia Diagnostics, Uppsala, Sweden) by a solid-phase, enzymelabeled chemiluminescent immunometric assay (by the Immulite 2000 Analyzer; Siemens, Cruinn Diagnostics Limited, Dublin, Ireland).

(b) Serum total ionized calcium concentration was determined by a spectrophotometer using a Hitachi 917 autoanalyzer (Hoffmann-La Roche Limited, Basel, Switzerland) and Roch reagents. A calciumbinding dye, orthocresolphthalein complex one, was used, which changes its color on binding to calcium. The intensity of the color formed is directly proportional to the concentration of calcium in the sample, and the absorbance of the color formed was determined at 650 $\mathrm{nm}$. A reference range of $8.5-10.5 \mathrm{mg} / \mathrm{dl}$ was used [14].

(c) Serum inorganic phosphorus levels were determined using a Hitachi 917 autoanalyzer and Roche reagents. This method is based on the reaction of phosphate ions with ammonium molybdate to form a phosphomolybdate complex, which is colorless and is determined directly by UV absorbance at $340 \mathrm{~nm}$. A reference range of 3.5-5.5 $\mathrm{mg} / \mathrm{dl}$ was used [15].

(d) Serum levels of 25(OH)D were assessed by an enzyme-linked immunosorbent assay (ELISA) using a competitive protein-binding assay kit for the measurement of $25(\mathrm{OH}) \mathrm{D}$, which is based on the competition of $25(\mathrm{OH}) \mathrm{D}$ present in the sample with $25(\mathrm{OH})$ vitamin tracer, for the binding pocket of vitamin D protein (VDBP, Gc globulin). Serum levels of 25(OH) D less than 30 and $10 \mathrm{ng} / \mathrm{ml}$ were defined as vitamin D insufficiency and vitamin D deficiency, respectively, whereas levels more than $30 \mathrm{ng} / \mathrm{ml}$ were defined as vitamin D sufficiency [16].

(e) Serum osteocalcin (OC) level as a bone formation marker was determined using an ELISA. Osteocalcin ELISA is based on the application of two highly specific monoclonal antibodies ( $\mathrm{M}$-abs) against human osteocalcin. An antibody recognizing the mid-region (amino acids 20-29) was used as the capture antibody and a peroxidase-conjugated antibody recognizing intact osteocalcin (amino acid 1-49) was used for detection; the N-terminal-mid fragment (amino acids 1-43) was also detected. A reference range of 0-100 ug/l was used [17].

\section{Statistical Analysis}

The results were analyzed using the statistical package for the social science version 10 (Echosoft Corp., Roswell, Georgia, USA). Quantitative and qualitative variables were described as mean \pm SD 
Page 3 of 6

and frequency and percentage, respectively. Student's $t$ test of two independent samples and the Pearson correlation coefficient test ( $r-$ test) were used to compare different variables against each other either directly or indirectly. Stepwise regression analysis was carried out to determine the relationship of data, where $\mathrm{P}$ less than 0.05 was considered significant for all comparisons.

\section{Results}

The mean age of the patients studied was $15.6 \pm 0.7$ years (range: 12.6-18.2 years). All patients fulfilled the DSM-IV criteria for AN. Amenorrhea was present as primary amenorrhea in seven of the 25 patients $(28 \%)$ or secondary amenorrhea in 15 of the $25(60 \%)$, and three patients were premenarchal (12\%). The mean duration of illness was $20 \pm 4$ months and the mean duration of amenorrhea was $23 \pm 5$ months.

Control individuals were $15.5 \pm 0.6$ years of age (range: $12.9-17.8$ years). All patients had a BMI SDS of $0.25 \pm 0.11$. Two 13.2 and 13.4years-old girls from the control group were premenarchal and the rest were postmenarchal adolescents and had regular menstrual periods.

Clinical data for patients and controls are summarized in Table 1. There was no significant difference in chronological age (CA) between patients and controls, whereas the $\mathrm{BA}$ to $\mathrm{CA}$ (BA/CA) ratio was significantly reduced in patients when compared with the controls (patients: $0.28 \pm 0.11$ years; controls: $1.01 \pm 0.04$ years; $\mathrm{P}=0.02$ ); height SDS did not differ between the two groups. Patients had significantly lower BMI (patients: $16.6 \pm 0.6 \mathrm{~kg} / \mathrm{m} 2$; controls: $21.8 \pm 0.5 \mathrm{~kg} / \mathrm{m} 2$; $\mathrm{P}=0.0001$ ) and BMI SDS (AN: $0.25 \pm 0.11$; controls: $1.15 \pm 0.01$, $\mathrm{P}<0.0001)$. Fat mass measured by DEXA was reduced to less than $50 \%$ in patients compared with the controls (patients: $7.8 \pm 0.7 \mathrm{~kg}$; controls: $18.8 \pm 0.9 \mathrm{~kg} ; \mathrm{P}=0.0001$ ), and percent body fat was significantly reduced in patients (patients: $16.8 \pm 1.2$; controls: $33.8 \pm 1.4$; $\mathrm{P}=0.0002$ ). Lean body mass was also significantly lower in patients (patients: $32.7 \pm 1.0 \mathrm{~kg}$; controls: $38.0 \pm 1.0 \mathrm{~kg}$; $\mathrm{P}=0.0001$ ) even after controlling for height and body weight.

\begin{tabular}{|l|l|l|l|}
\hline Variables & Patients $(\mathbf{n}=\mathbf{2 5})$ & Controls $(\mathbf{n}=\mathbf{3 0})$ & $\mathbf{P}$ \\
\hline $\begin{array}{l}\text { Chronological age } \\
\text { (years) }\end{array}$ & $15.6 \pm 0.7$ & $15.5 \pm 0.6$ & 0.49 \\
\hline Bone age (years) & $15.4 \pm 0.5$ & $15.5 \pm 0.4$ & 0.36 \\
\hline $\begin{array}{l}\text { Bone age/chronological } \\
\text { age }\end{array}$ & $0.28 \pm 0.11$ & $1.01 \pm 0.04$ & $0.02^{*}$ \\
\hline Height SDS & $1.01 \pm 0.28$ & $1.09 \pm 0.31$ & 0.86 \\
\hline BMI (kg/m2) & $16.6 \pm 0.6$ & $21.8 \pm 0.5$ & $0.0001^{\text {***}}$ \\
\hline BMI SDS & $0.25 \pm 0.11$ & $1.15 \pm 0.01$ & $<0.0001^{\text {*** }}$ \\
\hline
\end{tabular}

Table 1: Comparison of clinical and anthropometric data among patients with anorexia nervosa and controls. (Results are expressed as mean \pm SD. BMI, Body Mass Index; SDS, Standard Deviation Score.

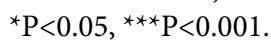

Bone density data for patients and controls are summarized in Table 2. Lumbar spine (L1-L4) BMD was significantly lower in patients (patients: $0.81 \pm 0.04 \mathrm{~g} / \mathrm{cm} 2$; controls: $0.95 \pm 0.03 \mathrm{~g} / \mathrm{cm} 2$; $\mathrm{P}=0.02$ ). In $40 \%$ of patients with $\mathrm{AN}$, lumbar BMD was more than 1 SDS under the reference healthy mean and $10 \%$ of patients had a lumbar BMD of more than 2 SDS under the normal mean.

\begin{tabular}{|l|l|l|l|}
\hline Variables & Patients $(\mathbf{n}=\mathbf{2 5})$ & Controls $(\mathbf{n}=\mathbf{3 0})$ & $\mathbf{P}$ \\
\hline $\begin{array}{l}\text { Lumbar spine BMD (g/ } \\
\text { cm2) }\end{array}$ & $0.81 \pm 0.04$ & $0.95 \pm 0.03$ & $0.02^{*}$ \\
\hline $\begin{array}{l}\text { Lumbar spine BMD z- } \\
\text { score }\end{array}$ & $0.2 \pm 0.2$ & $1.3 \pm 0.3$ & $0.003^{* *}$ \\
\hline Lumbar spine BMC (g) & $43 \pm 4$ & $51 \pm 3$ & $0.005^{* *}$ \\
\hline $\begin{array}{l}\text { Femoral neck BMD (g/ } \\
\text { cm2) }\end{array}$ & $0.25 \pm 0.01$ & $0.81 \pm 0.02$ & $0.0001^{* * *}$ \\
\hline $\begin{array}{l}\text { Femoral neck BMD z- } \\
\text { score }\end{array}$ & $0.5 \pm 0.4$ & $1.5 \pm 0.1$ & $0.001^{* *}$ \\
\hline Total BMD (g/cm2) & $1.01 \pm 0.01$ & $1.07 \pm 0.01$ & 0.58 \\
\hline TBMC (g) & $1718 \pm 42$ & $1890 \pm 59$ & $0.01^{*}$ \\
\hline Fat (kg) & $7.8 \pm 0.7$ & $18.8 \pm 0.9$ & $0.0001^{* * *}$ \\
\hline Percentage body fat (\%) & $16.8 \pm 1.2$ & $33.8 \pm 1.4$ & $0.0002^{* * *}$ \\
\hline Lean body mass (kg) & $32.7 \pm 1.0$ & $38.0 \pm 1.0$ & $0.0001^{* * *}$ \\
\hline
\end{tabular}

Table 2: Comparison of bone density and body composition data among patients with anorexia nervosa and controls. Results are expressed as mean \pm SD. BMC, Bone Mineral Content; BMD, Bone Mineral Density; TBMC, Total Body Bone Mineral Content. ${ }^{*} \mathrm{P}<0.05$,

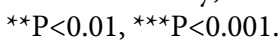

The lumbar BMD z-score was significantly reduced in patients with AN (patients: $0.2 \pm 0.2$; controls: $1.3 \pm 0.3 ; \mathrm{P}=0.003$ ). $\mathrm{Z}$-scores were below -1 in $50 \%$ and below -2 in $30 \%$ of patients. Lumbar BMC was also significantly lower in patients (patients: $43 \pm 4$ g; controls: $51 \pm 3$ $\mathrm{g} ; \mathrm{P}=0.005)$.

The reduction in femoral neck BMD was even more severe compared with the reduction in lumbar BMD (patients: $0.25 \pm 0.01 \mathrm{~g} /$ $\mathrm{cm} 2$; controls: $0.81 \pm 0.02 \mathrm{~g} / \mathrm{cm} 2 ; \mathrm{P}=0.0001$ ), with BMD much lower than 1 SDS in $55 \%$ and 2 SDS in $35 \%$ of patients. Similar results were obtained after height adjustment, indicating that low BMD was not an artifact. The BMD z-score of femoral neck was also significantly reduced in patients with $\mathrm{AN}$ (patients: $0.5 \pm 0.4$; controls: $1.5 \pm 0.1$; $\mathrm{P}=0.001$ ). Z-scores were below -1 in $60 \%$ and below -2 in $35 \%$ of patients with AN. Total body BMC was significantly lower in patients (patients: $1718 \pm 42$ g; controls: $1890 \pm 59 \mathrm{~g} ; \mathrm{P}=0.01$ ), whereas total body BMD did not differ significantly in patients. Differences in femoral neck BMD and total body BMC remained significant after controlling for height.

Serum hormone concentrations, biochemical data, and bone formation marker data are presented in Table 3. The level of serum basal GH was elevated significantly in patients compared with controls (patients: $6.9 \pm 2.1 \mathrm{ng} / \mathrm{ml}$; controls: $2.4 \pm 1.5 \mathrm{ng} / \mathrm{ml}$; $\mathrm{P}=0.02$ ). Serum IGF-1 levels were significantly reduced to less than $50 \%$ in patients compared with controls (patients: $237 \pm 52 \mathrm{ng} / \mathrm{ml}$; controls: $589 \pm 46$ $\mathrm{ng} / \mathrm{ml} ; \mathrm{P}=0.0001)$. In addition, IGF-1 levels in all patients were positively correlated with BMI $(\mathrm{r}=0.82 ; \mathrm{P}<0.0001)$, BMI SDS $(\mathrm{r}=0.94$; $\mathrm{P}<0.0001)$, percent body fat $(\mathrm{r}=0.73 ; \mathrm{P}=0.0001)$, and lean body mass $(\mathrm{r}=0.79 ; \mathrm{P}=0.001)$.

\begin{tabular}{|c|c|c|c|}
\hline Variables & $\begin{array}{l}\text { Patients } \quad \text { ( } n \\
=25)\end{array}$ & Controls $(n=30)$ & $\mathbf{P}$ \\
\hline $\mathrm{GH}(\mathrm{ng} / \mathrm{ml})$ & $6.9 \pm 2.1$ & $2.4 \pm 1.5$ & $0.02^{*}$ \\
\hline
\end{tabular}




\begin{tabular}{|c|c|c|c|}
\hline IGF-1 (ng/ml) & $237 \pm 52$ & $589 \pm 46$ & $0.0001^{* * *}$ \\
\hline Calcium (mg/dl) & $7.0 \pm 0.4$ & $9.2 \pm 0.1$ & $0.03^{*}$ \\
\hline Phosphorus (mg/dl) & $4.2 \pm 0.3$ & $4.6 \pm 0.3$ & 0.19 \\
\hline $\begin{array}{l}\text { 25-Hydroxyvitamin D } \\
\text { (ng/ml) }\end{array}$ & $22 \pm 3$ & $33 \pm 1$ & $0.04^{*}$ \\
\hline Osteocalcin (mg/l) & $33.9 \pm 6.1$ & $55.3 \pm 5.9$ & $0.02^{*}$ \\
\hline
\end{tabular}

Table 3: Comparison of serum hormone concentrations, biochemical data, and bone formation marker among patients with anorexia nervosa and controls. Results are expressed as mean \pm SD. GH, Growth Hormone; IGF-1, Insulin-Like Growth Factor $1 .{ }^{\star} \mathrm{P}<0.05,{ }^{*} \mathrm{P}<0.01$,

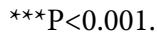

The level of serum ionized calcium was significantly lower in patients (patients: $7.0 \pm 0.4$; controls: $9.2 \pm 0.1 ; \mathrm{P}=0.03$ ), whereas serum phosphorus did not differ among patients and controls. The level of serum $25(\mathrm{OH}) \mathrm{D}$ was significantly lower in patients compared with controls (patients: $22 \pm 3$; controls: $33 \pm 1$; $\mathrm{P}=0.04$ ).

Similarly, the level of serum OC was significantly reduced in patients compared with controls (patients: $32.9 \pm 6.1$; controls: $55.3 \pm$ 5.9; $\mathrm{P}=0.02$ ). Moreover, there was a strong positive correlation between IGF-1 and OC in patients $(\mathrm{r}=0.865 ; \mathrm{P}=0.001)$, whereas that between GH and OC was not significant. In the control group, similar results were found, but the correlations were non-significant $(r=0.42$; $\mathrm{P}=0.2)$. In stepwise regression analysis, IGF-1 led to a $73 \%(\mathrm{r} 2=0.75$; $\mathrm{P}=0.001$ ) variation in the levels of $\mathrm{OC}$ in patients.

\section{Discussion}

We studied bone metabolism and density in adolescent girls with AN and compared them with those in age - and pubertal stagematched controls. Bone density was significantly reduced in patients. IGF-1 is a nutritionally dependent endogenous bone trophic factor with a defining role in bone [18]. Moreover, IGF-1 acts on preosteoblasts and osteoblasts, resulting in potent stimulation of bone synthesis [19].

Previous studies on bone metabolism in adolescents with AN were limited by the lack of information about specific markers of bone formation. Longitudinal data from healthy girls show that gain in bone mass is most pronounced between 11 and 14 years of age and decreases significantly after 16 years of age and/or 2 years after menarche [20]. Studies in adult women with AN have shown decreased bone turnover, with dysregulation between markers of bone formation and markers of bone resorption [21]. However, these data cannot be generalized to adolescent girls who are in a stage of rapid bone growth.

Abrams et al. [22] found that patients with AN have decreased absorption of calcium and increased levels of its excretion in the urine. Saggese et al. [23] reported low levels of carboxyl terminal propeptide of type 1 procollagen, a bone formation marker, in adolescent patients with AN and did not investigate other bone formation markers. Bone formation markers change from early to late puberty. Furthermore, the levels of bone formation and resorption in adolescents are higher compared with adult levels [24]. Adolescents with AN showed decreased height and the reason for this reduced height was not studied in this cross-sectional study and will require a longitudinal study. Reduced circulating IGF-1 leading to low bone formation may be a cause [25]; however, significant height difference was not found in our group of patients when compared with controls.

Our data showed markedly reduced body composition in patients, but there was a non-significant difference in total BMD, in agreement with the results of Bachrach et al. [2]. The reasons for relatively normal BMD in underweight individuals may include environmental exposure (i.e. prepubertal exercise) or genetic factors such as vitamin D receptor polymorphisms [26], but these were not systematically evaluated in this study. Our data show that significant spinal osteopenia is present in patients with AN compared with healthy adolescent girls. The results of lateral spine BMD, which is more related to trabecular bone [27], showed even more severe osteopenia.

An important finding in our study was that low serum calcium was prevalent in our study population of adolescent girls with $\mathrm{AN}$ as shown in other studies of adolescent girls [28], and a reduction in dietary calcium intake is a cause [29]. Calcium supplementation increases bone density in healthy adolescents and the resulting effect of calcium is dependent on the pubertal stage [30].

The level of serum $25(\mathrm{OH})$ D was significantly lower in patients with AN compared with controls, indicating that most adolescent girls require these important nutrients from food.

Although 25(OH) D affects osteoblasts and osteoclasts [31], a previous study has reported that low levels of serum OC in children with kwashiorkor are improved during nutritional rehabilitation and this improvement was not related to the serum level of $25(\mathrm{OH}) \mathrm{D}$ [32].

$\mathrm{GH}$ is a bone anabolic hormone through both direct and IGF-1mediated effects [33]. Girls with AN have lower levels of circulating IGF-1 compared with normal-weight girls of comparable age, despite higher GH levels, indicative of nutritionally acquired hepatic resistance to the effects of GH. Higher GH concentrations in girls with $\mathrm{AN}$ are a consequence of increased basal GH and also an increased frequency of GH secretory bursts. Although GH concentrations strongly predict the levels of bone turnover markers in normal weight girls, this association is completely lost in girls with $\mathrm{AN}$, indicative of a resistance to the effects of $\mathrm{GH}$ at the bone level [4].

These data were further understood by a report of a randomizedcontrolled study in which the changes in levels of IGF-1 (bone formation marker) did not differ in adult women with AN who were randomized to supra physiological doses of recombinant human GH compared with those randomized to placebo. These data show that in severe under nutrition, there is a fixed block in the production of IGF-1 by the liver that cannot be overcome by increasing the levels of GH [34].

IGF-1 is a positive predictor of bone turnover in girls with AN, and in a study by Sokya et al. [35], changes in the levels of IGF-1 over a period of 1 year were associated positively with changes in the levels of bone turnover markers over the same period. In adult women with AN, IGF-1 levels are associated independently with bone architectural parameters such as trabecular volume, thickness, and number, and inversely associated with trabecular separation, even after controlling for BMI. In addition, short-term administration of recombinant human rhIGF-1 in doses of $30-40 \mathrm{mg} / \mathrm{kg} /$ dose twice daily is successful in significantly increasing the levels of bone formation markers in both girls [36] and adult women with AN [21].

In our study, the bone formation index, OC, was significantly lower in adolescent girls with AN compared with healthy adolescents. In controls, there were high levels of bone formation, whereas low bone 
formation was found in patients. Formation marker in adolescents (OC) reflects bone mineralization. We suggest that in patients with $\mathrm{AN}$, remodeling continues, whereas bone formation is reduced.

We found a high negative correlation between IGF-1 levels and BMI, indicating that undernutrition reduces the levels of IGF-1 in adolescents with AN. This could be because of the fact that with the decrease in BMI, serum levels of IGF-1 decrease in a BMI-dependent manner. These data are in agreement with the findings of Loud et al. [37], who found low levels of serum IGF-1, and these low levels were correlated with low BMI in their patients with AN.

In our study, correlation of bone formation in patients with $\mathrm{AN}$ with significantly reduced levels of IGF-1 was found. Studies on nutritional causes of reduced IGF-1 in normal men showed that fasting for 5 days causes serumIGF-1 levels to decrease up to $36 \%$ of prefasting values and refeeding leads to an increase in serum IGF-1 levels, indicating that food intake increases serum IGF-1 [38].

Primary or secondary amenorrhea is commonly present inpatients with AN with resulting reduced estrogen levels. Reduced estrogen is hypothesized as a factor contributing toward low bone density in patients with AN. In adolescent girls with amenorrhea, lower lumbar bone density is present compared with control normal menstruating girls. These changes are reversible even before the return of menses during recovery of patients from AN [39].

Misra et al. [36] showed that rhIGF-1 therapy in patients with AN significantly increases serum levels of OC within 1 week of rhIGF-1 therapy before a significant increase in body weight and only after an increase in the levels of serum IGF-1. This suggests that bone formation marker production increases rapidly in response to the increase in the level of serum IGF-1 [40]. Patients with AN have disturbance in perception of body weight or shape and marked fear of gaining weight, which makes it difficult to advise them to increase their weight. They have to be informed that they are at a risk of developing osteoporosis, which is one of the most severe complications of AN.

\section{Conclusion}

This study describes low bone formation in adolescents with AN compared with age - and pubertal stage- matched adolescents. Serum levels of IGF-1 correlated highly with bone formation and thus IGF-1 measurement can be used as a marker for bone osteoblastic activity in patients with AN.

\section{References}

1. Wakeling A (1996) Epidemiology of anorexia nervosa. Psychiatry Res 62: 3-9.

2. Bachrach LK, Guido D, Katzman D, Litt IF, Marcus R (1990) Decreased bone density in adolescent girls with anorexia nervosa. Pediatrics 86: 440-447.

3. Milos G, Spindler A, Rüegsegger P, Seifert B, Mühlebach S, et al. (2005) Cortical and trabecular bone density and structure in anorexia nervosa. Osteoporos Int 16: 783-790.

4. Misra M, Klibanski A (2011) Bone metabolism in adolescents with anorexia nervosa. J Endocrinol Invest 34: 324-332.

5. DiVasta AD, Ringelheim J, Bristol SK, Feldman HA, Gordon CM (2007) Skeletal measurements by quantitative ultrasound in adolescents and young women with anorexia nervosa. J Pediatr 150: 286-290, 290.
6. J, Ziora K, Pluskiewicz W, Geisler G, Broll-WaÅska K, et al. (2007) Skeletal status and laboratory investigations in adolescent girls with anorexia nervosa. Bone 41: 103-110.

7. American Psychiatric Association. Diagnostic and statistical manual of mental disorders (1994) (4th ed). American Psychiatric Association, Washington DC.

8. Tanner JM, Whitehouse RH, Takaishi M (1966) Standards from birth to maturity for height, weight, height velocity, and weight velocity: British children. Arch Dis Child 41:613-635.

9. Cole TJ, Freeman JV, Preece MA (1995) Body mass index reference curves for the UK, 1990. Arch Dis Child 73: 25-29.

10. Greulich WW, Pyle SI(1959) Radiographic atlas of skeletal development of the hand and wrist. (2nd edn). Stanford University Press, Stanford, CA

11. Kalkwarf HJ, Zemel BS, Gilsanz V, Lappe JM, Horlick M, et al. (2007) The bone mineral density in childhood study: bone mineral content and density according to age, sex, and race. J Clin Endocrinol Metab 92: 2087-2099.

12. Binkovitz LA, Henwood MJ (2007) Pediatric DXA: technique and interpretation. Pediatr Radiol 37: 21-31.

13. El Maghraoui A, Roux C (2008) DXA scanning in clinical practice. QJM 101: 605-617.

14. Michaylova V, Ilkova P (1971) Photometric determination of micro amounts of calcium with arsenazo III. Anal Chim Acta 53:194-198.

15. Tietz L, ed. Clinical guide to laboratory tests. 4th ed. Philadelphia: Saunders WB Company

16. Scharla S, Chapuy M, Schattauer V (1996) Determination of 25-vitamin D in human serum and plasma. Exp Clin Endocrinol Diabetes 104: 289292.

17. Rosenquist C, Qvist P, Bjarnason N, Christiansen C (1995) Measurement of a more stable region of osteocalcin in serum by ELISA with two monoclonal antibodies. Clin Chem 41: 1439-1445.

18. Conover CA. The role of insulin-like growth factors and binding proteins in bone cell biology. In:Bileziikian JP, Raisy LG, Rodan GA, eds. Principles of bone biology. Academic Press, San Diego, USA

19. Jones JI, Clemmons DR (1995) Insulin-like growth factors and their binding proteins: biological actions. Endocr Rev 16: 3-34.

20. Theintz G, Buchs B, Rizzoli R, Slosman D, Clavien H, et al. (1996) Longitudinal monitoring of bone mass accumulation in healthy adolescents: evidence for a marked reduction after 16 years of age at the levels of lumbar spine and femoral neck in female participants. J Clin Endocrinol Metab 75:1060-1065.

21. Grinspoon S, Baum H, Lee K, Anderson E, Herzog D, et al. (1996) Effects of short-term recombinant human insulin-like growth factor I administration on bone turnover in osteopenic women with anorexia nervosa. J Clin Endocrinol Metab 81: 3864-3870.

22. Abrams SA, Silber TJ, Esteban NV, Vieira NE, Stuff JE, et al. (1993) Mineral balance and bone turnover in adolescents with anorexia nervosa. J Pediatr 123: 326-331.

23. Saggese G, Bertelloni S, Baroncelli GI, Di Nero G (1992) Serum levels of carboxyterminal propeptide of type I procollagen in healthy children from 1st year of life to adulthood and in metabolic bone diseases. Eur J Pediatr 151: 764-768.

24. Blumsohn A, Hannon RA, Wrate R, Barton J, al-Dehaimi AW, et al. (1994) Biochemical markers of bone turnover in girls during puberty. Clin Endocrinol (Oxf) 40: 663-670.

25. Nussbaum M, Baird D, Sonnenblick M, Cowan K, Shenker IR (1985) Short stature in anorexia nervosa patients. J Adolesc Health Care 6: 453-455.

26. Bass S, Pearce G, Bradney M, Hendrich E, Delmas PD, et al. (1998) Exercise before puberty may confer residual benefits in bone density in adulthood: studies in active prepubertal and retired female gymnasts. J Bone Miner Res 13: 500-507.

27. Finkelstein JS, Cleary RL, Butler JP, Antonelli R, Mitlak BH, et al. (1994) A comparison of lateral versus anterior-posterior spine dual energy $\mathrm{x}$-ray 
Citation: Hamza RT and Hewedi DH (2014) Insulin -like Growth Factor 1 in Adolescent Girls with Anorexia Nervosa: Relation to Bone Formation Parameters. J Psychol Abnorm Child 3: 128. doi:10.4172/2329-9525.1000128

Page 6 of 6

absorptiometry for the diagnosis of osteopenia. J Clin Endocrinol Metab 78: 724-730

28. Martin AD, Bailey DA, McKay HA, Whiting S (1997) Bone mineral and calcium accretion during puberty. Am J Clin Nutr 66: 611-615.

29. Lloyd T, Andon MB, Rollings N, Martel JK, Landis JR, et al. (1993) Calcium supplementation and bone mineral density in adolescent girls. JAMA 270: 841-844.

30. Chevalley T1, Rizzoli R, Hans D, Ferrari S, Bonjour JP (2005) Interaction between calcium intake and menarcheal age on bone mass gain: an eightyear follow-up study from prepuberty to postmenarche. J Clin Endocrinol Metab 90: 44-51.

31. Bouillon R, Okamura WH, Norman AW (1995) Structure-function relationships in the vitamin D endocrine system. Endocr Rev 16: 200-257.

32. Prudhon C, Sall G, Ndiaye B, Lemonnier D (1991) [Nutritional regulation of serum osteocalcin: study in kwashiorkor]. C R Acad Sci III 313: 233-238

33. Ohlsson C, Bengtsson BA, Isaksson OG, Andreassen TT, Slootweg MC (1998) Growth hormone and bone. Endocr Rev 19: 55-79.

34. Fazeli PK, Lawson EA, Prabhakaran R, Miller KK, Donoho DA, et al. (2010) Effects of recombinant human growth hormone in anorexia nervosa: a randomized, placebo-controlled study. J Clin Endocrinol Metab 95: 4889-4897.

35. Soyka LA, Misra M, Frenchman A, Miller KK, Grinspoon S, et al. (2002) Abnormal bone mineral accrual in adolescent girls with anorexia nervosa. J Clin Endocrinol Metab 87: 4177-4185.

36. Misra M, McGrane J, Miller KK, Goldstein MA, Ebrahimi S, et al. (2009) Effects of rhIGF-1 administration on surrogate markers of bone turnover in adolescents with anorexia nervosa. Bone 45: 493-498.

37. Loud KJ, Gordon CM, Micheli LJ, Field AE (2005) Correlates of stress fractures among preadolescent and adolescent girls. Pediatrics 115: e399-406.

38. Thissen JP, Ketelslegers JM, Underwood LE (1994) Nutritional regulation of the insulin-like growth factors. Endocr Rev 15: 80-101.

39. Audí L, Vargas DM, Gussinyé M, Yeste D, Martí G, et al. (2002) Clinical and biochemical determinants of bone metabolism and bone mass in adolescent female patients with anorexia nervosa. Pediatr Res 51: 497-504.

40. Fazeli PK, Klibanski A (2014) Determinants of GH resistance in malnutrition. J Endocrinol 220: 57-65. 